\title{
Trabalho e neodesenvolvimentismo Choque de capitalismo e nova degradação do trabalho no Brasil, de Giovanni Alves
}

Carla Beatriz de Paulo ${ }^{I}$

Em continuidade aos trabalhos anteriores, em especial o livro Dimensóes da Precarização do Trabalho - ensaios de sociologia do trabalho, publicado em 2013, o autor prossegue nas investigaçóes sobre as novas dimensóes da precarização estrutural do trabalho nos anos 2000. Essas reflexóes extrapolam o mundo do trabalho, alcançando também as novas determinações da reprodução social, a dinâmica política e o movimento das classes sociais

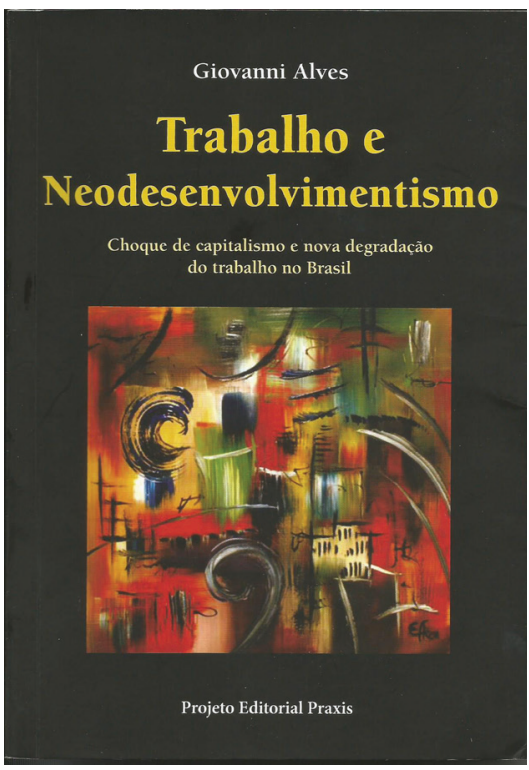
no Brasil contemporâneo.

As medidas neoliberais da década de 1990 propiciaram condiçôes materiais para a instauração do capitalismo flexível no Brasil. Primeiramente, esse novo modo de acumulação foi conduzido pela frente política do neoliberalismo, representada pelos governos Collor e

* Mestranda do Programa de Pós-Graduação em Política Social da Universidade de Brasília. 
FHC. No início dos anos 2000, a crise dos governos neoliberais levou à recomposição do bloco histórico do capitalismo flexível, agora conduzido pela frente política do neodesenvolvimentismo. A esse respeito, o autor faz uma importante observação metodológica ao diferenciar governo de Estado. Os governos de Lula e de Dilma seriam governos pós-neoliberais, na medida em que a sua programática política centrada no crescimento da economia com distribuição de renda e aumento do gasto público, não consistiria apenas na continuidade da ortodoxia neoliberal, mas sim em um novo padrão de desenvolvimento capitalista. É, nesse sentido, que o autor fala da ocorrência de um choque de capitalismo, realizado por esses governos, que propiciou a aceleração dos circuitos de valorização do capital no país.

Contudo, isso não significa dizer que os governos Lula e Dilma tenham rompido com o neoliberalismo. Pelo contrário, os governos pós-neoliberais optaram por manter o metabolismo político do Estado neoliberal herdado da década de 1990 e, em essência, o Estado oligárquico-burguês oriundo da ditadura-civil militar, o qual é evidenciado pela manutenção: (i) do pagamento de juros e amortização da dívida pública subordinada aos interesses do capital financeiro, o que contribui para as severas restriçôes orçamentárias que inviabilizam a execução de políticas sociais de caráter universal; (ii) do tripé da política econômica: metas de inflação, câmbio flexível e superávit primário; (iii) da estrutura burocrática do Estado brasileiro, com os seus traços oligárquicos e patrimonialistas; (iv) dos sistema de controle do gasto público normatizado pela Lei de Responsabilidade Fiscal; (v) do controle oligárquico dos meios de comunicação de massa, que contribuem amplamente para a manipulação da sociedade brasileira; e (vi) da sociedade civil neoliberal, fundada em valores individualistas e de mercado.

O crescimento econômico, na década neodesenvolvimentista, dá origem ao que Alves chama de nova macroeconomia do trabalho dos anos 2000, a qual assumiu dimensóes controversas que acabam por esgarçar as contradiçóes inerentes ao neodesenvolvimentismo. Por um 
lado, o período apresentou indicadores positivos, como o aumento do índice de formalização do trabalho, baixa taxa de desemprego, crescimento dos rendimentos médios reais, aumento real do salário mínimo e diminuição do tempo de procura de trabalho. Tais indicadores permitem afirmar que a macroeconomia do trabalho, na década de 2000, se apresenta de forma bastante distinta dos anos 1990, contribuindo para evidenciar os "tons de cinza” entre as duas frentes políticas que compóem o bloco histórico neoliberal.

Por outro lado, observa-se a persistência de aspectos estruturais e o surgimento de novos fatores que favorecem a precarização do trabalho no Brasil. Entre eles, destacam-se a flexibilização da remuneração, por meio da instituição de bancos de horas e remuneração variável e a flexibilização das formas de contração com a instituição de novas modalidades de contratos parciais e flexíveis. Ademais, outro aspecto ressaltado pelo autor diante dos indicadores favoráveis do mercado de trabalho da última década é a alta taxa de rotatividade, que decorre sobretudo das facilidades da demissão imotivada. Estes dados acabam por relativizar o crescimento da taxa de formalidade no mercado de trabalho brasileiro, uma vez que ela é calculada a partir do emprego formal e este obteve crescimento mais expressivo nos setores que historicamente possuem maiores níveis de rotatividade do trabalho.

A processualidade contraditória dessa nova macroeconomia do trabalho evidencia a dialética entre o velho e o novo, a continuidade e a ruptura no neodesenvolvimentismo, ao preservar elementos históri$\cos$ da flexibilidade da força de trabalho no Brasil e acrescentar outros aspectos da moderna precariedade no capitalismo flexível. A hipótese central da obra é que os anos 2000 são caracterizados pela consolidação de uma nova precariedade estrutural no Brasil, a qual constitui uma nova morfologia social da exploração do trabalho assalariado nos locais de trabalho reestruturados, cuja principal característica é a flexibilidade. Essa nova precariedade estrutural do século XXI significa não apenas a precarização salarial, inerente ao modo de produção capita- 
lista, mas também a precarização existencial e a precarização do homem-que-trabalha.

A crise estrutural do capital, ao gerar a necessidade irremediável de alcançar patamares cada vez mais altos de desvalorização da mercadoria força de trabalho, aliada ao surgimento da maquinofatura, foram os dois fatos históricos que levaram à emergência da nova precariedade estrutural no capitalismo atual. A maquinofatura, ao unir a manufatura e a grande indústria, alterou profundamente as relaçóes entre a força de trabalho e o meio de trabalho, dando origem ao modo de vida just-in-time, que constitui uma nova organização do modo de vida nas condições do capitalismo flexível, baseado na disseminação do espírito do toyotismo na totalidade da vida social. O modo de vida just-in-time leva à ocorrência do fenômeno da vida reduzida, promovendo a precarização existencial. Já a precarização do homem-que-trabalha decorre da convergência da precarizaçáo salarial e existencial, culminando no adoecimento por motivos laborais e na degradação da pessoa humana. Essa forma de precarização pode ser evidenciada pelo aumento de doenças ocasionadas pelo trabalho, sobretudo os transtornos mentais.

Alves argumenta que o neodesenvolvimentismo acirrou as contradiçóes da ordem burguesa hipertardia, ao optar por um "reformismo fraco", nos termos de André Singer, adotando políticas redistributivas focadas no subproletariado, evitando o confronto de interesses com o capital financeiro-industrial e o acirramento da luta entre capital e trabalho. Ocorre que essa opção pelo subproletariado, devido aos constrangimentos orçamentários impostos pela dívida pública, tem impedido a realização de políticas sociais que contribuam para a satisfação de necessidades sociais de saúde, educação e transporte público das demais classes sociais.

Evidência dessas contradiçóes são as manifestaçóes de junho de 2013, que são denominadas pelo autor como as revoltas do precariado, o qual constitui uma camada social da classe do proletariado, composta por jovens altamente escolarizados que estáo inseridos em condiçóes de 
trabalho e vida precários ou desempregados. Para Alves, o precariado surge no Brasil, na década de 1980, e não é, portanto, um fenômeno que tem origem no neodesenvolvimentismo, embora assuma dimensões expressivas no período atual. Isso ocorre porque o crescimento econômico brasileiro, na década de 2000, tornou o fenômeno mais visível, na medida em que a nova dinâmica do mercado de trabalho brasileiro fez com que uma larga parcela de jovens altamente escolarizados ficasse desempregada ou inserida em relaçóes de trabalho precárias. Para o autor, os jovens que fazem parte do precariado constituem os "órfẫos" do neodesenvolvimentismo, na medida em que "cumpriram tudo aquilo que a ordem burguesa receitou para obterem sucesso, mas não encontraram um lugar ao sol com a incapacidade do próprio sistema inclui-los como força de trabalho produtiva” (p. 186).

Os "rolezinhos", por sua vez, foram protagonizados por outra camada social do proletariado, denominada "proletaróides", termo da sociologia weberiana ressignificado pelo autor. Nesse contexto, "proletaróide" faz referência ao proletariado precário com consciência de classe burguesa, sendo permeado pelos valores burgueses de "classe média". Os "proletaróides" são, então, os jovens assalariados pobres da faixa de renda $\mathrm{C}$ e $\mathrm{D}$, que foram recentemente incluídos no circuito de consumo pelo choque de capitalismo promovido pelo neodesenvolvimentismo, que levou à intensificação do fetichismo da mercadoria, por conta do aumento do consumo. Os "rolezinhos" expuseram o problema da corrosão da coisa pública e da degradação dos espaços públicos de sociabilidade, que é evidenciada pelo aumento exponencial dos espaços privados de consumo e lazer, notadamente os shopping centers.

Assim, a partir dos fenômenos recentes da "nova classe trabalhadora", os protestos de julho de 2013 e os "rolezinhos", o autor amplia o nível de concreção da classe do proletariado, revelando o complexo de camadas sociais que a compóe. Dessa forma, a obra presta importante contribuição à compreensão das mudanças na dinâmica das classes sociais impulsionadas pelo neodesenvolvimentismo como novo padrão 
de desenvolvimento capitalista no Brasil. As reflexôes do autor evidenciam também a processualidade contraditória entre a posição objetiva e a posição subjetiva das camadas sociais do proletariado, que contrapóem, de um lado, a sua inserçãoo proletária nas relaçôes de trabalho e, por outro, as suas aspiraçóes de consumo e de ascensáo social provenientes das ideologias das classes médias. Fiel à tradição lukacsiana, o autor se afasta tanto do determinismo econômico vulgar quanto do idealismo voluntarioso, analisando a atual situação nacional a partir das múltiplas determinações entre política, economia, cultura e sociedade, buscando assim a máxima concretude para o desvelamento da ontologia do ser social contemporâneo.

ALVES, Giovanni. Trabalho e neodesenvolvimentismo - choque de capitalismo e nova degradação do trabalho no Brasil. Bauru: Canal 6, 2014. 